SB 419

.F97

Copy 1

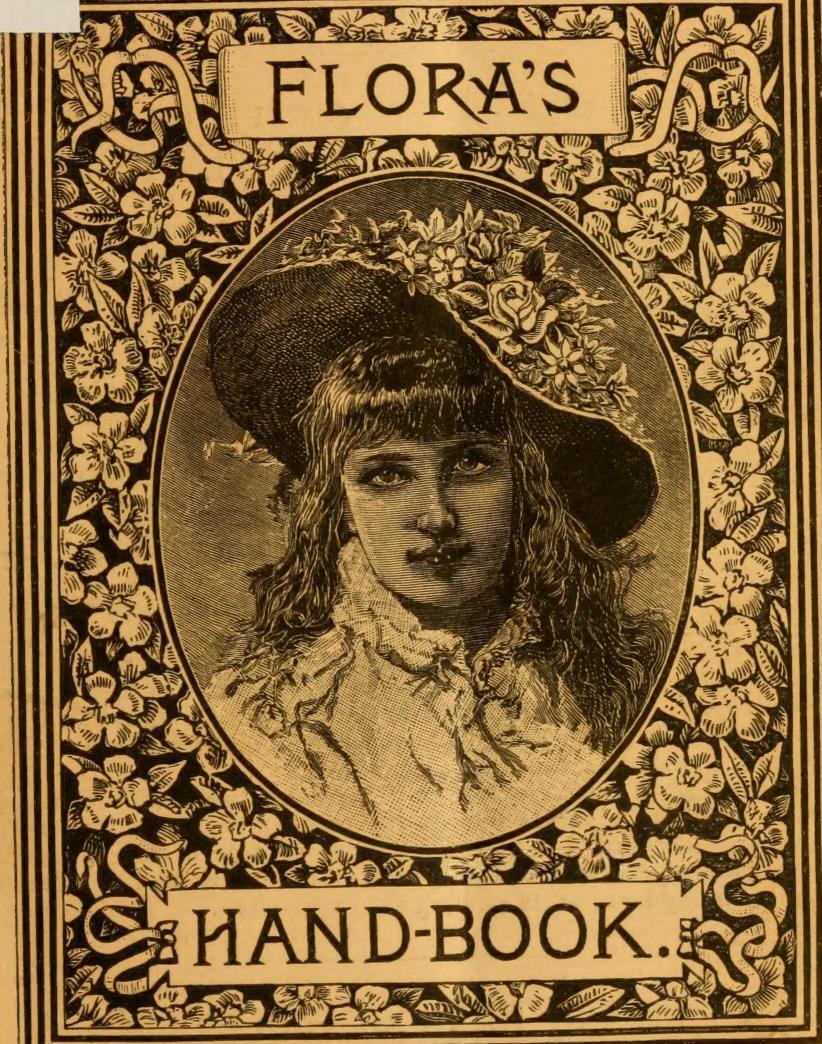




\section{Beautiful Flowers.}

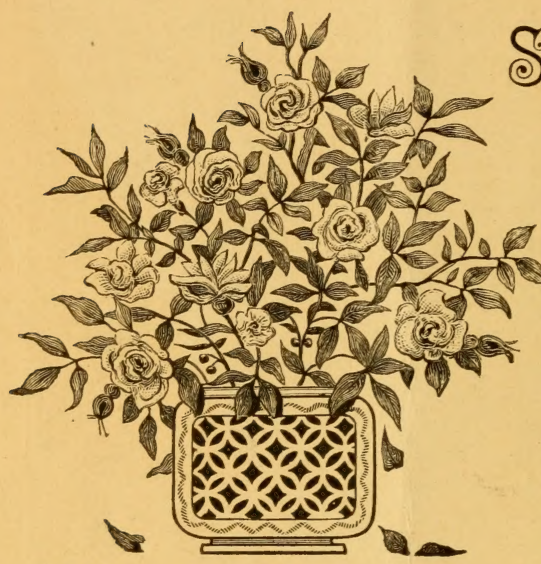

G.HRUBS and plants of all

(C) kinds, to bloom freely, must be in a high state of vitality; and when in a healthy condition it is only natural that the flowers will be of a bright and attractive hue. To secure the vigorous condition described, with dark, luxuriant foliage, and large and richly colored flowers, it is necessary that they should receive by root absorption, the elements to develop strength, which will induce a rapid growth, and, as a necessity, the most beautiful foliage will follow.

While the rays of the sun, air and moisture are altogether necessary, at the same time the proper food must be given plants, or they cannot thrive properly. This is furnished in the Clark's Cove Plant FrrTILIzER, which is fully described on page 2 of this issue. This compound is likewise a valuable insecticide.

We can highly recommend this preparation to all who love and grow Hlowers, and however limited the number of plants they may possess, this compound will exable them to secure such pleasure through brilliant coloring and exquisite fragrance, as will more than return the outlay incurred in making the cxperiment.

\section{Presented by Clark's Cove Guano Co.}




\section{FLORA'S \\ $\mathrm{H} A \mathrm{~N} D-\mathrm{B} O \mathrm{~K}$.}

A GUIDE TO

FLOWER CULTURE

AND

\section{WINDOW GARDENING,}

WITH

BOTANICAL NOTES.
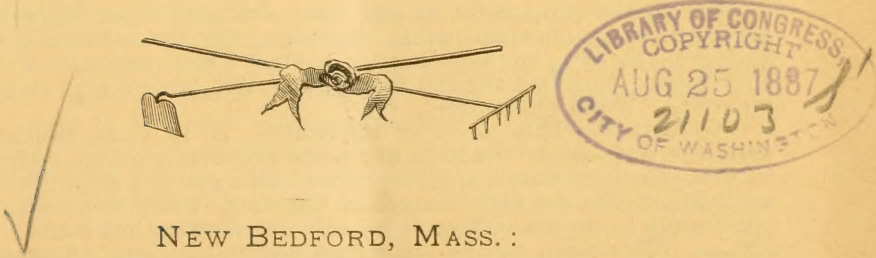

CLARK'S COVE GUANO COMPANY,

26 Burling Slip, New York. 


\section{FOR HOUSE OR CONSERVATORY.}

\section{The Clark's Cove Plant Fertilizer.}

An Odorless Plant Food and Insecticide for Pot Plants, Vines, Choice Shrubs, ete.

Develops Increased Vitality and Strength, Rapid Growth, Rich, Dark Foliage, with

Perfection of Form.

Producing Luxuriant Flowers of Great Brilliancy and Exquisite Fragrance.

In Canisters (aceompanied with a copy of FLonA's HAND-Book - a guide to. Flower Culture and Window Gardening with Botanical Notes). Price, 25 eents.

Sold by Retail Merchants.

Sample Cans for Trial mailed on receipt of five two-cent postage stamps.

Agents wanted. Territory guaranteed. Address,
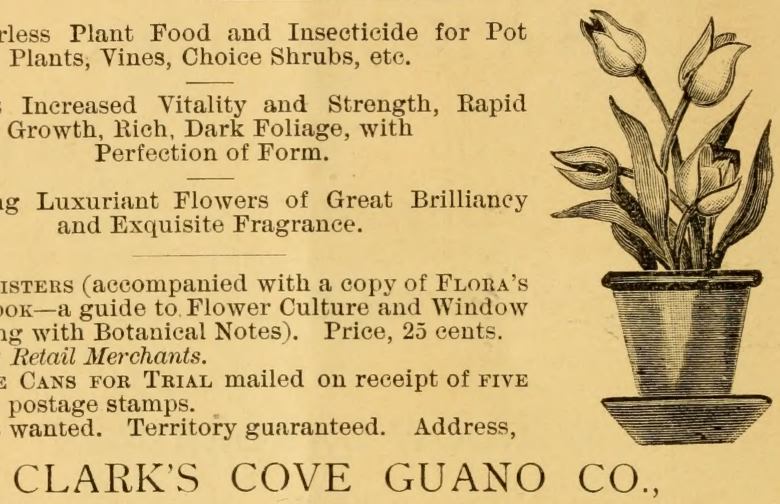

New Bedford, Mass.

OR 26 BuRLiNG Silip, N. Y.

\section{DIRECTIONS FOR USE.}

Use in the proportion of one teaspoonful to a pot eight inches in diameter, every alternate week. Sprinkle over the surface, around and away from the stem, but avoiding any contact ; then with a stick or a blunt knife blade, work into the soil very lightly, not, however, so as to disturb the roots. Water moderately.

As a STEEP. - This mode of application is, in some respects, more desirable, and can be made in about the proportion of one tablespoonful to two quarts of water, applying from half a gill to a gill of the liquidaecording to the size and strength of the plant-every few days. Let the application be on the surface of the soil, not allowing any contact with the foliage. This steep can be made in a covered tin can, and any unused kept for later use. SHAKE WELL BEFORE APPLICATION.

Do NOT EXCEẼ THE QUANTITIES NAMED IN EITHER APPLICATION. 


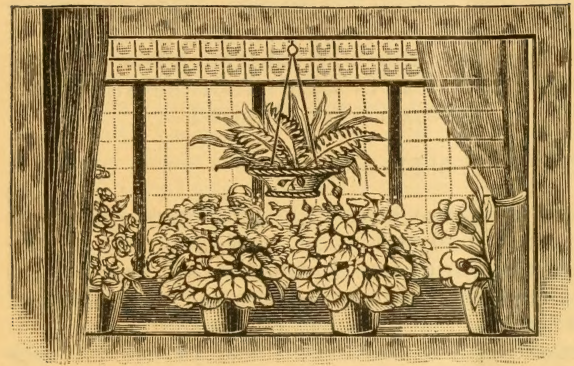

\section{BRILLIANT \\ FLOWERS}

IN THE

\section{CASEMENTT.}

I $\mathrm{N}$ cultivating plants in 1 pots, boxes or other similar vessels, we confine their roots to a very circumscribed area, preventing them from wandering to any considerable distance in search of nutriment; consequently, we must place the elements which they require near by, or within easy reach. The roots of plants may be confined within a very limited area, provided nutriments and moisture are supplied them in liberal quantities.

\section{SOIL.}

The soil used for house plants in general, should be rich and of a rather loose and pliable nature, or at least light and porous enough to permit the water applied to the surface from time to time to pass down slowly, but surely, to the very bottom. Sods gathered from an old pasture and placed in a heap until they are thoroughly decomposed, make an excellent potting-soil ; but leaf-mold from the woods, with a little old manure and a trifle of sand added, also makes an excellent material for this purpose. "For a large proportion of window plants the texture of the soil should be such that when firmly pressed between the two hands it will hold together when laid down. If it crumbles and falls apart by its own weight it is too light, and a little sticky loam or clay should be added; but if the lump is firm and somewhat like putty in grain it will dry too hard, and more vegetable mold should be added. Soil when gathered from deep shade in the woods or city yards should be placed in heaps exposed to the sun and rain for a few weeks, or even months, before using it for pot plants of any kind, for earth long excluded from sunlight needs to pass through a kind of sweetening process before being used for window plants. The heap of 
potting soil can be frequently worked, and its texture, if not just right, be improved by adding whatever materials are required, even to mixing with it some kind of concentrated fertilizer. Florists make a practice of preparing their potting soil several months in advance of the time it is needed for use, and those who cultivate a few or many window plants should keep a little heap in some out-of-the-way corner of the yard, where it can be drawn upon when required.

\section{LIGHT AND HEAT.}

Flowering plants must of course have light, but there are many kinds that will thrive in a half shady situation, or if they only get the direct rays of the sun for an hour or two during the day, but a south window is always preferable to one facing east or west; still either of the latter will answer, for one can readily select plants adapted to such exposures. The ferns, mosses, ivies, and even many of the cactuses thrive in positions where they are shaded the greater part of the day.

Heat is of course necessary to all plants during the period of active growth, and tender kinds when at rest should not be subjected to a temperature much below $40^{\circ}$ Fahrenheit. While growing and blooming, ordinary house plants require a temperature from $55^{\circ}$ to $75^{\circ}$, or a degree of heat which would be generally considered by most persons as comfortable while seated in a room. Some kind of plants, it is true, will thrive in a much lower temperature than others, and the Camelias, Tea Plant and Azaleas will often bloom freely in water in a temperature that would be disasterous to the Heliotropes and Coleuses. But most persons after a little experience will be able to make selecticns of such plants as thrive best with them-conditions being so variable that no uniform rule can be given that would serve as a guide for all.

\section{BOXES AND POTS.}

A person cultivating window plants has a choice of an immense number of designs in the way of fancy boxes, shelves, hanging brackets, Wardian cases, flower stands and ornamental flower pots. Long, narrow boxes, made to fit the window and rest on the window sill, are convenient for holding a number of plants, which may be planted in the soil with which the box is filled, or the pots plunged in the soil, or even surrounded with moss from some swamp. Plants that will bear crowding may be set quite thickly in such boxes- a few that grow quite tall and smaller kinds that bear considerable shade set in around the base. 
These window boxes may be a foot or móre in width, and as long as the window is wide, the depth varying from five to ten inches, according to the size of the plants cultivated. The inside of the box should be lined with zinc, tin, or some similar metal to prevent leakage, and before the soil is placed in it the bottom should be covered with fine pieces of broken pots or bricks for drainage. As no moisture can escape through the bottom or sides of these metal-lined boxes, less water will be needed by the plants growing therein than by plants grown in single pots. Slate or soapstone boxes are preferable to those made of wood and lined with metal, but they are usually more expensive. Side boxes, brackets upon which to set one or more single pots, and various devices of this kind may be employed to suit one's fancy and to give to a window an artistic appearance, and at the same time not over-crowd or exclude the light from the plants needing it most.

If it is not desirable to fasten boxes or other similar fixtures to the window frames, then a narrow table may be used instead of the window sill to hold the boxes and pots, and even standards may be fastened to the table to hold brackets or wire frames, etc., on which to train vines. In some respects the table is preferable to permanent fixtures in the window, for in cold nights during the winter it can be readily moved away from the window and placed in the warmest part of the room.

Where pots are employed, the common earthen pot, such as used by the florists, is the best for all kinds of plants cultivated in soil, because they are porous, allowing moisture to pass off through their sides as well as through the hole in the bottom, placed there to insure good drainage. But fancy glazed pots may be employed for plants requiring a large amount of moisture, like the Callas, or for forcing Crocuses, Hyacinths, and similar kinds of bulbs in spring.

\section{POTTING PLANTS.}

Amateurs, or persons who have had little experience in raising plants in pots, are inclined to use much larger pots than is necessary, no doubt thinking that the more room the roots have in which to spread out, the better. This is an error, for in cultivating plants in pots we not only aim to economize space, but to control the growth of the roots and all parts of the plant.

If small plants are placed in large pots the roots extend rapidly in a lateral direction until they strike the sides, and then throw out numerous rootlets which bend around, keeping close to the pot, while the inner or center parts of the ball of earth is, comparitively speaking, unoccupied by any feeding roots. The proper way to proceed with 
small plants, whether raised from seeds or cuttings, is to place them at first in pots not more than two or three inches in diameter, and when these are filled with a solid ball of roots and soil shift into larger pots, that is, those about one inch larger than those from which they are removed. From three-inch pots shift into four-inch, and when the roots crowd knock out and place in five-inch, and prcceed in this manner until the plants are full grown, or as large as desired. With such plants as Geraniums, Fuchsias, Heliotropes and Abutilons, eightinch pots will answer very well for plants when a year old, if the soil is rich and fertilizers are added to supply the plants with the necessary nutriment. When the plants become too large for eight-inch pots they may be given larger ones, or a part of the roots cut away and the stem cut to almost any required height.

\section{WATERING PLANTS.}

When or how often house plants should be given water is a difficult question to answer, because conditions are extremely variable, and in a dry, warm room plants will need more water than when kept in a cool one. Plants when growing rapidly also need more water than when making a slow growth or are at rest. Then again there are some plants that will thrive in soil almost constantly saturated with water, while others would soon perish under such conditions. But as a rule plants with a large expanse of leaf, like the Geranium, should be kept well supplied with moisture while growing and blooming, and the soil kept constantly moist, but not perfectly saturated. In a very dry, warm room they may need water once a day, but usually it need not be applied oftener than every

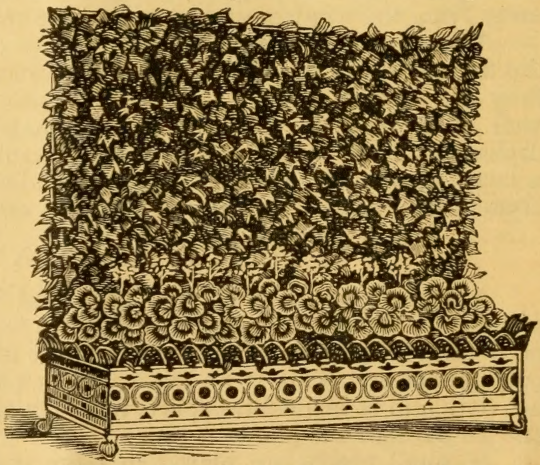
other day, and then enough should be given to wet the soil throughout, not merely to the depth of an inch or more on the top. The more rapid and vigorous the growth the more water will be required, because a large amount is imbibed by the roots and passes off through the leaves. 
Very cold water is likely to check growth, and the temperature should not be much lower than tbat of the room in which the plants are growing, and if several degrees warmer, so much the better. Plants should be watered overhead often enough to keep the leaves clean and free from di.st.

\section{INJURIOUS INSECTS.}

The more vigorous the plants the better can they resist the attacks of insects, but there are a few species of plant-pests that seem to thrive best on healthy and rapid growing plants, but these are among those most readily destroyed. The red-spider and the aphis are the two most common insects infesting house plants. The former seldom injures vigorous growing healthy plants that are kept in a moist atmosphere, while the latter is always most troublesome under exactly the opposite conditions, but is readily destroyed by tobacco water or tobacco smoke. The plants may be fumigated with tobacco smoke, or the leaves syringed with strong tobacco water until the insects and their eggs are destroyed. If tobacco is objectionable, then Persian insect powder or California Buhach may be applied, although the latter is most expensive.

\section{SELECTION OF WINDOW PLANTS.}

Geraniums are general favorites, as they bloom freely and their flowers are very showy, while the plants usually succeed even when the conditions are not the most favorable.

Those varieties with ornamental leaves, like the Mountain of Snow, Happy Thought and Mrs. Pollock, make very showy window plants even when not in bloom. The variegated, scented, zonale and ivy leaved varieties are also very attractive. Monthly Carnations are also favorite house plants, blooming freely during the winter months and almost in any moderately warm room. These require fertilizing applications to keep up a constant succession of flowers.

Callas, Fuchsias, Azaleas, Heaths, Cape Jasmine, Bouvardias and Begonias are free blooming plants of easy culture. Also, Cyclamens, Chrysanthemums, Chinese Primroses, Hyacinths, and other bulbs; Heliotropes, and such roses as the Bengal, Bourbon, and Tea varieties, and Camellias, will be found well adapted to window cultivation.

These also might be added, but they require a higher temperature, and are more difficult to grow than the preceding: Stephanotis, Tuberoses, Poinsettias, Orchids and Lycopodiums. They should never have a lower temperature than $60^{\circ}$ at night. 
For climbing and trailing plants the Ivies of various species Smilax, Spiderworts, (Tradescantias), Climbing Groundsel, Maurandias, and many other similar kinds may be employed, and they usually succeed with, or under ordinary care.

Ferns of various kinds may be cultivated for the beauty of their foliage and graceful habit of the plants. They require considerable moisture and a rather light and porous soil. They will also thrive when planted rather close or crowded, and several kinds may be grouped together in boxes if these are used instead of single pots. It is not every handsome plant, unfortunately, that will thrive in a window garden.

\section{CACTUSES.}

Of all cultivated plants the Cactus will withstand the most neglect, and still as a family they yield a greater number of large and brilliant colored flowers than any other. There are vast numbers of small species and varieties well adapted to window culture, and all live to a great age, and some produce a succession of flowers in spring, each of which is as large, and in some instances larger than the parent plant. The best species for house culture are to be found among what are called the Melon Cactuses (Melo-Cartus), Mother Cactuses (Mammallaria), and the Leafy Cactuses (Epiphyllums). The members of the two former genera are mainly small and of a globular form, and some bloom profusively when not larger than a small or medium sized orange or apple. The Leafy Cactuses grow larger, with somewhat flattish stems or leaves. The flowers are of various colors, from deep violet purple to the purest white, and some are deliciously fragrant. In size the flowers vary from an inch up to eight or more.

Cactuses require very little water when at rest, for in their native countries sometimes a whole year passes without a shower; consequently in cultivating such plants we may give them a long rest by withholding water, and still not seriously weaken their vitality. During the winter months they should be kept in a warm place and just sufficient water supplied to prevent shrivelling. As the spring approaches apply water more freely, and this will cause them to bloom, at least those known as the free blooming varieties. Some of the small and rather delicate growing species are grafted upon strong stocks, forming elegant miniature Cactus trees.

\section{TAKING UP PLANTS.}

Such plants as Geraniums, Heliotropes, Petunias, Verbenas, etc., that have been growing in the garden during the summer, and are 
wanted for house culture during the winter, may be taken up and potted in the fall, but sometime before frosts come to scorch or kill the leaves.

The best time to lift such plants is after a heavy rain, when the soil about the roots is soaked with water; but if rain does not fall, then the plants may be watered freely a few hours before they are taken up, always allowing sufficient time for the water to pass down among the roots before disturbing the plants. Cut around the roots at some distance from the plant with a sharp spade, then raise the ball of earth gently, and if too large to go into the pot take off a little all around the ball, preserving the roots, as these can be bent around within the pot. Pack the soil firmly around the roots when placed in the pot and then apply water freely overhead as well as to the soil in the pot. Set the plants in the shade, or even in a dark room, for a day or two after potting them, as this will in a great measure prevent wilting and insure the production of new feeding roots. In pruning off the tops, always cut in long and straggling branches, and endeavor to give the plant a symmetrical shape. Remove all dead and sickly leaves from time to time, as may be necessary for the good appearance of the plants.

Another plan is this: such plants intended for house cultivation in winter, when set out in the preceding May, should be placed in good sized pots and buried in the ground to the top, or on a level with the surface. The hole in the bottom of the pot should be stopped up, however, that the roots cannot strike through ; and it would be well to turn the pots round once or twice during the summer, so as to break off any roots that may reach through the bottom. If this is not done, it will be almost as difficult to transfer into boxes, as would attend a hasty transfer of plants late in September, and which, almost under the best circumstances, will wilt seriously and possibly die. The best aspect for exposure is a window facing due south.

\section{FROSTED PLANTS.}

If by neglect plants become slightly frosted or frozen during the winter, they should be immediately sprinkled with water at a temperature of about $50^{\circ}$, and then entirely excluded from light for a few hours, after which keep in the shade for a day or two before placing in the window. All severely injured twigs and leaves should be removed.

\section{TREATMENT OF GERANIUMS.}

In the end of August take off cuttings with a clean horizontal cut close under a joint, insert them in pots filled with very sandy soil, and 
make them firm in the soil and keep them close to and around the edge of the pot, give them gentle watering, and put in a shady place for a few days, when they may be exposed to the weather. Or you may first put them in a border in place of pots, but in either case pot off as soon as rooted: next spring put them into 6 -inch or 8-inch pots in good loam, leaf mould, and some sand; use the fertilizer sparingly. They should be stopped occasionally, and when out of bloom place them out of doors to ripen the wood, then in August cut back to within about three eyes of the old wood, and you can utilize the trimmings for a good lot of cuttings. When cut back, water rather sparingly until they start again, and, when the young shoots are one inch long, pot them in pots two sizes smaller than those they were in before, by shaking out a lot of the old soil, and trimming some of the roots. Take them in September into the house and keep them rather dry until spring, when the same routine is to be observed as with the cuttings. They can be grown most successfully by the above routine. 


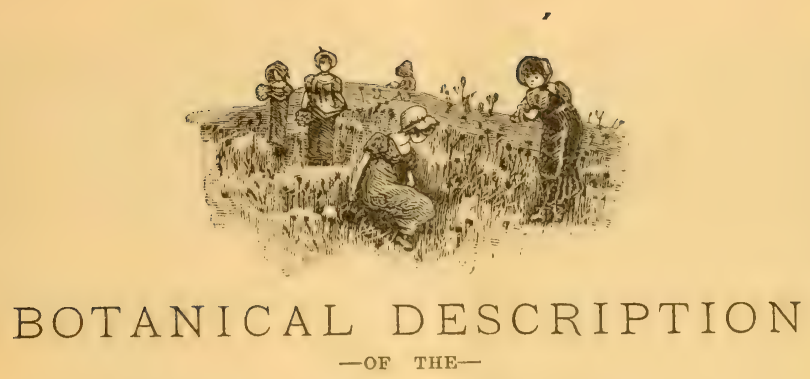

VARIOUS PARTS OF A FLOWER.

In a perfect flower there are seven parts, viz. :
1. The Calyx.
2. The Corolla.
3. The Stamens.
4. The Pistil.
5. The Pericarp.
6. The Seed.

7. The Receptacle.

Many flowers are deficient in some of their parts, but the stamens and pistils are essential and to be found in all, either in fiowers on the same plant, or in different individuals of the same species on separate plants. The calyx, cup or empalement is the outer part of the flower, formed of one or more greenish leaves, sustaining the corolla at the bottom, and enclosing it entirely before it expands, as you may remark in the Rose and Geranium.

The Calyx is either-

A cup, as in the Polyanthus.

A fenee, as in the Carrot.

A catkin, as in the Willow.

A sheath, as in the Daffodil.

A husk, as in Oats, Wheat or Grasies. A veil, as in Mosses.

A curtain, as in Mushrooms.

The blossom, petals, or corolla, is that beautifully colored part of a flower which first attracts the attention, and is regarded by common olservers as the flower itself; it serves as a protection to the important parts of fructifieation, the stamens and pistils, and falls ofl when they attain maturity.

The stamens or chives are composed of two parts, one long and thin, by which they are fastened to the bottom of the corolla, and called the filament: the other thicker, placed at the top of the filament, callerl the anther. Each anther is a kind of hox, which opens when it is ripe and throws out a yellow dust, ealled pollen or farinia. This dust is absorbed by the pistil, and passing through it reaches the germ, and vivifies the 
seed, which, without this process, would be imperfect and barren. When the flowers grow on separate plants, the pollen is often carried by inseets, as it adheres to their wings while they are extracting honey. It is also possible that an attraction may subsist between the parts which may draw the pollen, floating in the air, to the pistils of its own species. The pistil, or pointal, is composed of three parts, the germen, which stands at the bottom and contains the embryo seeds; the style, which is placed on the germen, a hollow tube of various figures and lengths, and sometimes wholly wanting; the stigma, which is placed on the top of the style, or, if there be none, on the germen.

The seed-vessel, or pericarp, is the germen enlarged as the seeds increase in size. The seed-vessel is divided into nine kinds :

Capsule, as in the Poppy.

Nut, as in the Filbert.

Drupe, as in the Cherry.

Berry, as in the Strawberry
Pome, as in the Apple.

Silique, as in the Wallflower.

Silicle, as in Honesty.

Legume or Shell, as in the Pea.

Cone, as in the Fir.

The seeds, or fruit, resemble the eggs of animals and contain the rudiments of a new vegetation. The seed is composed of several parts : first, the heart, or principle of life, contained within the lobes; this also consists of two parts, the plume which ascends and becomes the future stem, and the beak which descends and becomes the root. Second, the lobes, which supply the heart with nourishment till it is capable of deriving it from the earth. Third, the eye or external mark where the seed was fastened within the seed-vessel. Fourth, the seed-coat, or proper cover to the seed. The seed itself is sometimes crowned with the cup of the flower, and sometimes winged with a feather or thin membrane, which assists the wind to waft or disperse it to a distance.

The base, or receptacle, is that part by which the whole fructification is supported; it is very remarkable in the Artichoke, consisting of that part which is eaten.

The nectary, or honey cup, is an appendage with which some flowers are furnished, containing a small quantity of sweet juice, from which the bees colleet their rich treasures. It is very conspicuous in some flowers, as in the Nasturtium, Crown Imperial, but less visible in others, and in some appears to be entirely wanting. In the Dove-footed Cranesbill there are five yellowish glands which serve as a nectary. The use of this organ is supposed to be that of a reservoir for the nourishment of the tender seed-bud.

According to the Linnæan mode of classification, it is necessary to give a brief account of those parts of the flowers on which this classification depends, and also a list of the classes themselves.

Before the time of Linnæus the study of botany was involved in the greatest obscurity, from the utter want of regularity in the various systems which had been propounded by philosophers. The great Swedish naturalist undertook to remove this difficulty and devised a new mode of classification which, though arbitrary, and in some respects defective, is 
certainly the most generally approved of any which have hitherto aypeared. Linnæus made his system to depend upon the part of a plant necessary to propagation; namely, the stamens and pistils. On this plan he divided the vegetable world into twenty-four classes; the first thirteen of which depend upon the number of stamens, and derive their names from two Greek words, the latter of which, Andria, means husband, and refers to the stamen itself, while the former expresses the number of stamens of which the class is composed, thus:-

Class. Name.

1. Monandria,

2. Diandria,

3. Triandria,

4. Tetrandria,

5. Pentandria,

6. Hexandria,

7. Heptandria,

8. Octandria,

9. Enneandria,

10. Decandria,
Number and position of stamens.

one stamen.

two stamens.

three "6

four "

five " "

six " "

seven "

eight "،

nine "

ten "

11. Dodecandria, from eleven to nineteen stamens, inclusive, provided they are disunited.

12. Icosandria, twenty stamens, standing on the calyx and blossom.

13. Polyaudria, from twenty stamens upwards, standing on the receptacle.

14. Didynamia, or two powers, contains all plants which have four stamens, of which two are shorter than the others. Labiate or lif)shaped, and Personate or masked flowers, are included in this class.

15. Tetradynamia, or power of four. Its character is distinguished by six stamens, four of which are long and the remaining two short. The Cruciform, or cross-shaped species, are contained in this class.

16. Monadelphia, one brotherhood. In this class the filaments are united at the bottom, but separate at the top, as in the Geranium.

17. Diadelphia, or two brotherhoods. The filaments are united at the bottom into two bundles, as in the Sweet Pea.

18. Polyadelphia, or many brotherhoods. The filaments are united at the bottom, into three or more bundles.

19. Syngenesia, contains the compound flowers, as the Daisy.

20. Gynandria, many stamens growing on the pistil itself, as in the Orehis.

21. Monœecia, or one house. Flowers, some bearing stamens only, and some pistils, being produced on the same plant.

22. Dioceia, two houses. Flowers, some producing stamens only, and others pistils, growing on different plants.

23. Polygamia, provides for the only remaining case that can possibly: occur, and consists of flowers with stamens and pistils in separate, as well as on the same, plants. 
24. Cryptogamia, plants whose flowers are not perceptible to the naked eye, though there is good reason to believe that no plant exists without the essential parts which constitute a flower. Ferms, Mosses and Seaweeds belong to this class.

To these classes Linureus has added the Palm Trees, which he calls Princes of India. They are distinguished by bearing their parts of fructification on a spadia or receptacle, within a spathe or sheath, remarkable for their prodigious height, distinguished by an unvaried, undivided perennial trunk, crowned at top by an evergreen tuft of leaves, and rich in the production of large and fine fruit.

The orders which compose the classes were arranged by Linneus as follows:

Mouogynia,* one pistil.

Digynia, two pistils.

Trigynia, three pistils.

Tetragynia, four pistils.

Pentagynia, five pistils.

Hexagynia, six pistils.

Heptagynia, seven pistils.

Oetagynia, eight pistils.

Enneagynia, nine pistils.

Decagynia, ten pistils.

Dodecagynia, twelve to twenty pistils.

Polygynia, many pistils.

In the 14th class, Didynamia, the orders, which are two, depend upon the seeds being contained in seed-vessels or not. They are called: Gymnospermia, when the seeds are naked, and Angiospermia, when they are enclosed in a seed-vessel.

The orders of the 15th class, Tetradynamia, are also two, and are determined by the shape of the seed-vessels or pods. The first has broad short pods, and is called Siliculosa. The second has long pods, and is named Siliquosa.

In the 16 th, 17 th and 18 th classes, the orders are known by the number of stamens.

The 19th elass, Syngenesia, contains five orders :

1st. Polygamia Equalis, having all the florets alike.

2d. Polygamia Superflua, florets of the centre perfect; those of the margin having pistils only, but all producing perfect seeds, as in the Daisy.

3d. Polygamia Frustranea, florets of the centre perfect, those of the margin neuter, as in the Blue Bottle.

4th. Polygamia Necessaria, florets of the disk with stamens only; those of the margin with pistils only, as in the Marigold.

5th. Polygamia Segretata, several florets in one common calyx, yet each floret having a calyx for itself, as in the Globe Thistle.

The $22 \mathrm{~d}$ and $23 \mathrm{~d}$ classes have their orders chiefly distinguished by their stamens.

The 24th class has five orders, eomprehending:

1st. Filices, or Fern.

2d. Musci, or Mosses.

3d. Hepatier, or Liverworts. 4th. Algæ, or Flags.

5th. Fungi, or Mushrooms.

*'The orders of the first thirteen classes, distinguished by the number of the pistlls contained in the flower, and by adding the word gynia (a Greek term for wife) to the number, may be easily remembered. 


\section{I RECTIONS \\ $-\mathrm{FOR}-$ \\ PLANTING SEEDS and GROWING FLOWERS.}

PREPARED SPECIALLY FOR NEW BEGINNERS.

Neatness in a flower garden is of the first importance. Weeds and stones must be removed as fast as they appear. The soil should be good and rich. If it be hard clay, it can be improved by sand or lime dust.

Dig deeply, and pulverize the soil as much as possible. A good plan in a city garden is to dig trenches, throwing the dirt up on one side. Put coal ashes in the bottom of the trench, and throw the earth back. The ashes in the bottom act as a drain, and the process of throwing out and putting back makes the earth loose and fine.

The time for sowing flower seeds is from the 15th of April to the 15 th of May. The seed may be sown in a bed-made for the purpose -in little drills or rows, having a stake at the head of each row, marking the name of the variety. The space between the rows should be carefully weeded and kept clean, and in dry weather the little plants watered.

When the plants are a few inches high, they can be dug up and planted where they are to stand in the garden. In planting, make a puddle in the bottom of the hole, place the plant in, and cover up with loose earth. Do not plant too closely. Give them plenty of water in the evenings.

Some sow the seeds where they are to stand, and thin them out as they grow-always pulling out the weaker plants, and letting the strong stand.

Many flower seeds fail by being planted too deep. The seeds should be just covered with the soil, and no more. Sow only part of each paper, so that in case of failure there is some left to sow again. As the plants grow, some will require the aid of small sticks or stakes, and vines should be assisted in climbing.

Those who have no garden or yard may grow their plants in boxes, placed on window sills or other outdoor situation where they can have the morning sun if possil)le.-Landreth's Circular. 


\section{DIAL OF FLOWERS.}

'Twas a lovely thought to mark the hours

As they floated in light away,

By the opening and the folding flowers

That laugh to the Summer's day.-Mrs. Hemans.

TIME OF OPENING.

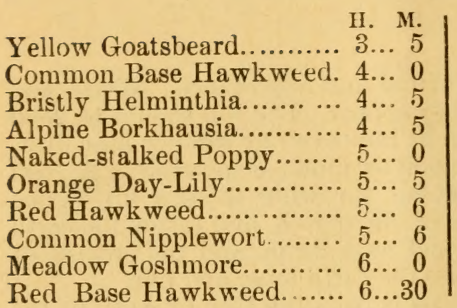

H. M. White Water-Lily.......... $7 \ldots .0$ White Spiderwort........... 7... 0 Garden Lettuce.............. 7... 0 Common Pimpernel........ 7.. 8 Mouse-Eared Hawkweed. . 8... 0 Field Marigold............... 9... 0 Purple Sandwort............ 9...10 Ice Plant....................... 10.. 0 Red Sandwort.............10...0

\section{TIME OF CLOSING.}

\begin{tabular}{|c|c|}
\hline Bristly Helminthia.......... $12 \ldots . .0$ & Ice Plant. \\
\hline Alpine Agathysus...........12... 0 & White Spiderwort............... $4 \ldots$ \\
\hline Creeping Mallow........ & Meadow Goshmore. \\
\hline Red Pink.................. $1 \ldots 0$ & White Water-Lily... \\
\hline Red Boxhawkweed.......... 1... 0 & Naked-stalked Poppy. \\
\hline Bearded Mesembryanthe- & Copper-colored Day Lily... $7 \ldots$ \\
\hline Purslane.... & Yellow Goatsbeard.. \\
\hline Marigold........ & Garden Lettuce..... \\
\hline can Marigold.... & on Sowthistle \\
\hline
\end{tabular}




\section{THE CLARK'S COVE GUANO CO. \\ Capital, $\$ 800,000.00$.

\author{
MANUFACTURERS AND COMPOUNDERS OF
} \\ FULL STRENGTH \\ COMPLETE FERTILIZERS, FOR \\ $\begin{aligned} \text { FIELD, LAWN, } & \text { GARDEN, ORCHARD AND } \\ & \text { GRAPERY. }\end{aligned}$}

edmund grinnell, President. Samuel ivers, Treasurer. V. F. HATCH, MaNager.

General Offices : New Bedford, Mass.

Geo. W. Kirke, - - Gen. Sales Agent, - - New York. John M. Green, - Southern Manager, - ATLANTA, GA. Wm. A. Gassaway, - Sales Agent, - - Baltimore, MD. A. A. Mitchell, - Special Agent, - - Portland, ME.

Works: South Dartmouth, Mass.

CAPACITY-With AUXiliary PLANTS-60,000 Tons PER ANnUm.

Complete Lawn and Garden Fertilizer, Odorless and Highly Concentrated.

One Package Contains the Strength of One Load of Digested Compost. Free from Filthy Litter or Bad Odors and from Insect Germs.

Put up in Small and Convenient Packages. Saves Money, Time and Labor. 
LIBRARY OF CONGRESS

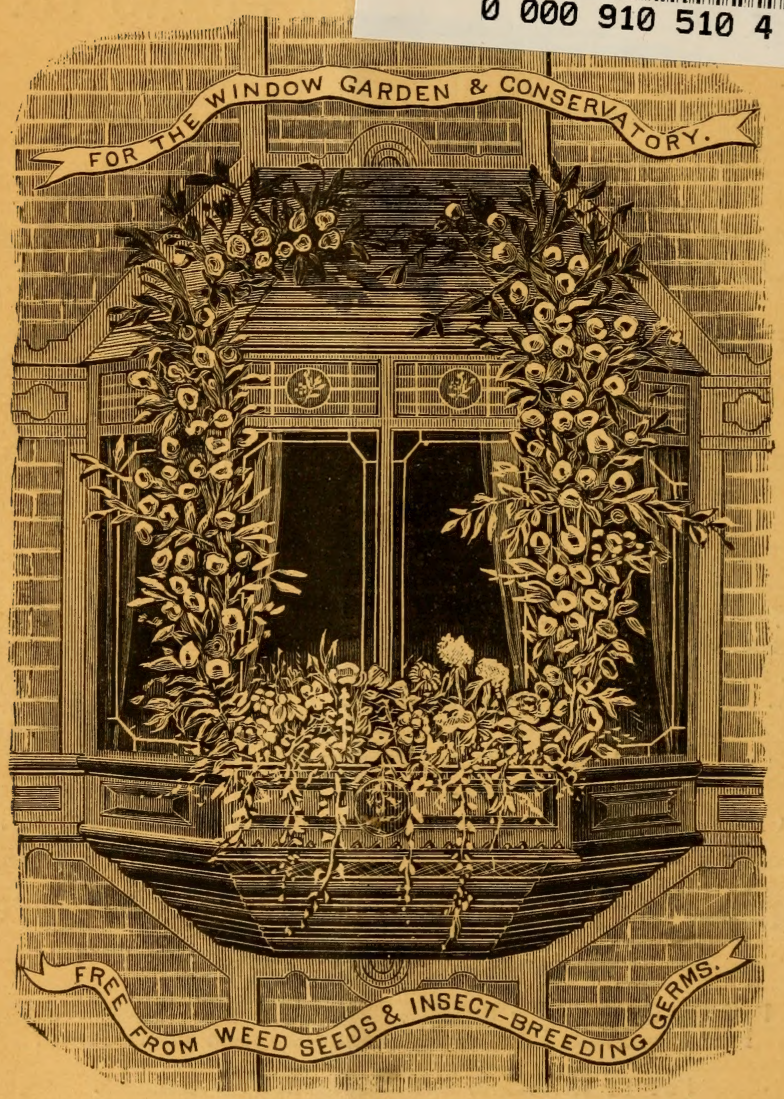

00009105104

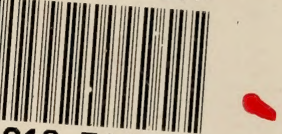

